\title{
PENGARUH MODEL DISCOVERY DAN CONVENTIONAL LEARNING TERHADAP MOTIVASI SISWA DAN HASIL BELAJAR
}

\author{
Anisa Yuliana, Sulis Janu Hartati \& Sri Yuni Hanifa \\ Universitas Dr. Soetomo \\ fanisayulia@gmail.com
}

\begin{abstract}
Abstrak
Pendidikan Pancasila dan Kewarganegaraan (PPKn) merupakan mata pelajaran inti dan sudah diajarkan kepada siswa sejak Sekolah Dasar hingga jenjang yang lebih tinggi. Oleh karena itu perlu adanya Model Pembelajaran dan motivasi agar peserta didik tidak merasa jenuh dan mengalami kesulitan karena proses penyampaian materi yang monoton dalam belajar PPKn. Penelitian ini menggunakan metode penelitian Quasi Experimental Design. Tujuan penelitian ini adalah 1) Mengetahui pengaruh model pembelajaran Discovery dan Conventional Learning terhadap hasil belajar PPKn siswa UPTD SMPN 1 Labang Bangkalan, 2) Mengetahui pengaruh model pembelajaran Discovery dan Conventional Learning terhadap motivasi siswa UPTD SMPN 1 Labang Bangkalan, 3) Mengetahui interaksi antara model pembelajaran Discovery dan Conventional Learning terhadap motivasi siswa dan hasil belajar PPKn UPTD SMPN 1 Labang Bangkalan. Populasi dalam penelitian ini adalah seluruh kelas VII sebanyak 240 siswa, yang menjadi sampel adalah kelas VII a dan kelas VII ${ }^{\mathrm{b}}$, penentuan sampel dilakukan dengan menggunakan Purposive Sampling. Hasil penelitian menunjukkan 1) terdapat pengaruh Model Pembelajaran Discovery dan Conventional Learning terhadap hasil belajar diperoleh nilai sig. sebesar 0,000<0,05, kedua Ada pengaruh model pembelajaran Discovery dan Conventional Learning terhadap motivasi siswa diperoleh nilai sig. sebesar $0,001<0,05$, dan yang ketiga Ada interaksi antara Model Pembelajaran dan motivasi terhadap hasil belajar yang dibuktikan dengan nilai sig. 0,038 < 0,05 sesuai dengan kriteria uji Two Way Anova.
\end{abstract}

Kata kunci: Discovery Learning, Conventional, Motivasi dan Hasil Belajar

\begin{abstract}
Pancasila and Citizenship Education (PPKn) is a core subject and has been taught to students from elementary school to higher levels. Therefore, it is necessary to have a learning model and motivation so that students do not feel bored and experience difficulties due to the monotonous process of delivering material in learning Civics. This study uses a Quasi Experimental Design research method. The aims of this study were 1) to determine the effect of the Discovery and Conventional Learning learning models on the Civics learning outcomes of UPTD SMPN 1 Labang Bangkalan students, 2) To determine the effect of the Discovery and Conventional Learning learning models on the motivation of UPTD SMPN 1 Labang Bangkalan students, 3) To determine the interaction between models Discovery learning and Conventional Learning on student motivation and learning outcomes of PPKn UPTD SMPN 1 Labang Bangkalan. The population in this study was all class VII as many as 240 students, the samples were class VIIa and class VIIb, the determination of the sample was carried out using purposive sampling. The results showed 1) there was an influence of the Discovery Learning Model and Conventional Learning on the learning outcomes obtained by the value of sig. of $0.000<0.05$, secondly there is an influence of the Discovery and Conventional Learning learning models on student motivation, the value of sig is obtained. of $0.001<0.05$, and the third There is an interaction between the learning model and motivation on learning outcomes as evidenced by the value of sig. $0.038<0.05$ according to the criteria for the Two Way Anova test.
\end{abstract}

Keywords: Discovery Learning, Conventional, Motivation and Learning Outcomes

\section{PENDAHULUAN}

Pendidikan merupakan pengetahuan belajar di berbagai lingkungan yang harus dilalui seumur hidup dan berpengaruh positif bagi perkembangan individu. Karena dalam pendidikan memiliki makna 
perubahan pada pengetahuan, nilai, dan keterampilan yang dibutuhkan. Oleh karena itu pendidikan memiliki peran penting dalam membentuk karakter manusia yang berkualitas (Subagio, 2011).

Pendidikan

Pancasila

dan

Kewarganegaraan dapat memberikan implikasi terhadap proses pembelajaran di sekolah, dimana pendidikan kewarganegaraan merupakan mata pelajaran yang berfokus untuk membentuk karakter warga negara untuk memahami serta dapat melaksanakan hak dan kewajibannya sebagai warga Negara Indonesia yang sesuai dengan amanat Pancasila dan UUD 1945 (Depdiknas, 2006:49) (Nurgiansah, Pratama, et al., 2021).

Berdasarkan hasil ulangan harian PPKn kelas VII Semester Ganjl tahun 2019/2020 di UPTD SMPN 1 Labang diperoleh hasil bahwa $60 \%$ nilai siswa dibawah KKM (Kriteria Ketuntasan Minimal), dan 40\% nilai siswa di atas KKM. Dimana KKM yang digunakan adalah 70.

Dengan adanya model pembelajaran Discovery Learning ini diharapkan mampu mengarahkan siswa agar bisa berinteraksi seperti mencari jawaban dari pertanyaan yang diberikan oleh gurunya sesuai dengan tingkatan usia siswa tersebut. Biasanya yang perlu diperhatikan dalam suatu proses pembelajaran yaitu bahasa yang digunakan sebagai alat komunikasi, dan guru harus memberikan sebuah motivasi kepada siswa agar memperoleh hasil belajar yang baik serta optimal. Sehingga kita akan mengetahui perbedaan antara motivasi dengan hasil belajar dalam menggunakan model pembelajaran Discovery Learning tersebut.

Selain metode pembelajaran, guru juga menerapkan motivasi untuk membangkitkan motivasi belajarnya karena motivasi ini dianggap penting bagi mereka, karena untuk bisa memahami suatu pelajaran siswa harus terlebih dahulu senang dan berminat untuk belajar (Nurgiansah \& Sukmawati, 2020). Sehingga setelah mendapatkan motivasi siswa dapat menerima dan menganalisis materi yang diberikan oleh guru. Guru sebagai seorang pendidik harus bisa memahami dan mampu memilih metode pembelajaran yang cocok dan efektif sehingga membuat siswa dapat berkembang dengan baik.

Motivasi terbagi menjadi dua, yaitu motivasi intrinsik dan motivasi ekstrinsik. motivasi intrinsik, yaitu motif-motif yang menjadi aktif atau timbulnya tidak ada pengaruh dari luar, karena motivasi ini timbul dari dalam diri seseorang dengan adanya dorongan untuk mengerjakan sesuatu. Motivasi intrinsik dapat dikatakan sebagai bentuk motivasi yang terdapat aktivitas dimulai dan dilanjutkan berdasarkan suatu dorongan dari dalam diri dan secara mutlak yang berkaitan dengan aktivitas belajarnya (Nurgiansah, Hendri, et al., 2021). Kedua, motivasi ekstrinsik yaitu motif-motif yang aktif atau timbulnya karena terdapat dorongan atau dukungan dari luar. Motivasi ekstrinsik juga bisa dikatakan sebagai suatu bentuk motivasi yang seluruh aktivitasnya diawali dan dilanjutkan berdasarkan dorongan atau dukungan dari faktor lain yang tidak berkaitan dengan dirinya (Nurgiansah, 2021).

Dari permasalahan di atas dan juga keinginan peneliti untuk mengatasi permasalagan yang harus dihadapi siswa dalam memahami materi pembelajaran khususnya pada kompetensi Transformasi dan juga untuk menumbuhkan motivasi siswa dalam belajar yaitu dengan menciptakan suasana pembelajaran yang berorientasi pada siswa, maka peneliti mengangkat judul "Pengaruh Model Pembelajaran Discovery, Conventional Learning terhadap Motivasi siswa dan hasil belajar PPKn UPTD SMPN 1 Labang Bangkalan". 


\section{METODE PENELITIAN}

Pada penelitian ini pendektakan kuantitaif digunakan oleh peneliti dengan analitik kuantitatif dalam penerapannya dilakukan melalui tahapan kerja atau struktur kinerja yang cenderung untuk menguji teori-teori tertentu dengan fokus pada variabel atau hubungan antar variabel.

Metode yang digunakan dalam penelitian ini yaitu Quasi Experimental Design, dengan tujuan untuk melihat perbedaan pengetahuan dari dua kelas dengan perlakuan yang berbeda. Sugiyono (2017:79) mengatakan bahwa penelitian ini aka nada dua kelompok yang tidak dipilih secara random. Kedua kelas tersebut diberikan pretest untuk melihat kemampuan awal dan untuk melihat perbedaan dari keduanya. Dimana kelas A menggunakan model pembelajaran Conventional dan kelas B menggunakan model pembelajaran Discovery Learning dan diakhiri dengan tes akhir untuk masing-masing kelas.

Populasi merupakan daerah generalisasi yang terdiri atas objek atau subyek yang memiliki kualitas dan ciriciri tertentu yang ditetapkan oleh peneliti untuk dipelajari dan kemudian ditarik kesimpulannya (Sugiyono, 2016:80). Populasi dalam penelitian ini mencakup seluruh kelas VII UPTD SMPN 1 Labang Kabupaten Bangkalan pada tahun 2019/2020 dengan jumlah siswa sebanyak 240 siswa.

Sampel merupakan bagian dari jumlah dan ciri-ciri yang dimiliki oleh populasi. jika populasi besar, tidak mungkin peneliti mempelajari secara keseluruhan yang terdapat pada populasi, seperti karena dana yang terbatas, tenaga dan waktu, maka peneliti dapat menggunakan sampel yang diambil dari populasi. Dalam penelitian ini yang menjadi sampel adalah kelas VIIa dan kelas VIIb UPTD SMPN 1 Labang. Dalam menentukan sampel dilakukan dengan menggunakan Purposive Sampling, yaitu teknik pengambilan sampel sumber data dengan pertimbangan tertentu (Sugiyono, 2016:85).

Instrumen penelitian ini, terdiri dari 2 data instrumen. Instrumen tersebut yaitu instrumen tes dan instrumen non tes. Sedangkan data dari hasil tes tersebut berupa hasil belajar yang akan digunakan untuk mengukur pemahaman siswa pada materi pembelajaran, sedangkan data dari hasil non tes berupa angket untuk melihat perkembangan motivasi siswa. Sebelum instrument tes dilakukan dan diberikan ke siswa dikelas eksperimen dan kontrol tersebut dilakukan validitas oleh guru yang berpengalaman, selain uji validitas intumen tes juga di uji dengan uji reliabilita dan homogenitas. Pengujian dilakukan dengan bantuan aplikasi IMP SPSS Versi 24.0 for windows.

Untuk menjawab hipotesis yang dilakukan dalam penelitian ini yaitu dengan uji Anova dua jalur. Namun analisis tersebut tidak dihitung secara manual, akan tetapi menggunakan bantuan Statistical Purpose for Social Science versi 2.4 atau yang lebih dikenal dengan SPSS 2.4 .

\section{HASIL PENELITIAN DAN PEMBAHASAN Hasil Penelitian}

Aspek kognitif merupakan hasil dari pengalaman belajar siswa yang didapatkannya selama proses belajar mengajar, aspek ini merupakan hasil dari pemberian instrument tes tulis berbentuk pilihan ganda sebanyak 20 butir yang diberikan kepada siswa setelah diberikan perlakuan dengan pembelajaran menggunakan model discovery dan conventional learning. Data yang didapatkan yaitu data skor hasil belajar dari 60 siswa yang terdiri dari 30 siswa kelompok $_{1}$ dengan model pembelajaran Discovery Learning dan 30 siswa 
kelompok $_{2}$ dengan model Conventional. Posttes bertujuan untuk mengetahui sejauh mana pengaruh model pembelajaran terhadap hasil belajar PPKn siswa.

\section{Pembahasan}

Dari hasil perhitungan data penelitian yang di dapat dari posttest model pembelajaran Discovery Learning diperoleh nilai tertinggi sebesar 100 dan nilai terendah 75 , nilai rata-rata $(X)$ sebesar 86,00 standar devisiasi (s) sebesar 6,215 dan varians $\left(\mathrm{s}^{2}\right)$ sebesar 38,621. Selanjutnya, data penelitian yang di dapat dari posttest pembelajaran menggunakan model Conventional diperoleh nilai tertinggi sebesar 85 dan nilai terendah 75 , nilai rata-rata $(X)$ sebesar 79,83 standar devisiasi (s) sebesar 3,824 dan varians $\left(\mathrm{s}^{2}\right)$ sebesar 14,626.

Selanjutnya dilakukan Uji normalitas dengan tujuan untuk melihat apakah intrumen yang diberikan kepada responden memiliki distribusi normal atau tidak. dengan kriteria taraf signifikan 0,05 , apabila nilai sig. yang didapat $>0,05$ maka intrumen tersebut memenuhi kriteria untuk dikatakan normal, namun apabila nilai sig. yang didapat $<0,05$ maka intrumen tersebut tidak memenuhi kriteria untuk dikatakan normal, selain itu, uji normalitas ini dapat dilihat melaui interpretasi diagram Q-Q Plot dengan dasar pengambiklan keputusan apabila data menyebar menjauh dari garis diagonal maka data dianggap tidak berdistribusi normal tapi jika data mendekati garis diagonal atau persebaran searah dengan garis diagonal, maka data tersebut memenuhi kriteria normal. Pengujian dilakukan pada taraf kepercayaan 0,05 dari tabel 4.8 dapat disimpulkan bahwa hasil uji normalitas nilai pretest dan Posttest model pembelajaran Conventional berdistribusi normal karena memenuhi kriteria dilihat dari tabel kolmogorov-Smirnov 0,395 > 0,05 . Sedangkan pada hasil uji normalitas nilai pretest dan Posttest model pembelajaran Discovery Learning berdistribusi normal karena memenuhi kriteria dilihat dari tabel kolmogorovSmirnov 0,291 >0,05.

Uji homogen varian ini sangat dibutuhkan oleh peneliti untuk melakukan perbandingan terhadap dua sampel atau lebih agar ketika terjadi perbedaan tidak disebebkan oleh data kasar untuk menguji homogenitas varian digunakan, berikut hasil dari pengujian homogenitas pada soal butir sebelum diterapkan strategi pembelajaran.

Tabel 1. Hasil Uji Homogenitas

\begin{tabular}{|l|l|l|l|}
\hline \multicolumn{4}{|c|}{ Dependent Variable: Hasil Belajar } \\
\hline F & df1 & df2 & Sig. \\
\hline 1.292 & 29 & 30 & 0.245 \\
\hline
\end{tabular}

Berdasarkan kriteria uji homogenitas, bila nilai sig. > 0,05 maka data diasumsikan memiliki varians yang sama, tetapi apabila nilai sig. $<0,05$ maka data diasumsikan memiliki varians yang tidak sama. Hasil pengujian homogenitas diatas menunjukan bahwa data memiliki varians yang sama dengan nilai sig. 0,245 yang artinya lebih besar dari 0,05 atau $(0,245>0,05)$.

Selanjutnya peneliti menggunakan uji Two Independent sample t-Test untuk mengetahui apakah ada perbedaan hasil belajar antara Model pembelajaran konvensional dengan discovery learning. Berikut ini hasil uji t.

Tabel 2. Hasil Uji Two Independent Sample t-test

\begin{tabular}{|c|c|c|}
\hline \multirow{2}{*}{$\begin{array}{c}\text { hasil belajar } \\
\text { PPKn }\end{array}$} & \multicolumn{2}{|c|}{$\begin{array}{c}\text { t-test for Equality of } \\
\text { Means }\end{array}$} \\
\cline { 2 - 3 } & $\mathrm{t}$ & $\begin{array}{c}\text { Sig. (2- } \\
\text { tailed) }\end{array}$ \\
\hline $\begin{array}{l}\text { Equal variances } \\
\text { assumed }\end{array}$ & -4.629 & 0 \\
\hline
\end{tabular}




\begin{tabular}{|l|l|l|}
\hline $\begin{array}{l}\text { Equal variances } \\
\text { not assumed }\end{array}$ & -4.629 & 0 \\
\hline
\end{tabular}

Berdasarkan hasil pengujian hipotesis dengan kriteria Uji Independent T-Tes apabila nilai sig. $<0,05$ maka terdapat perbedaan, dan sebaliknya apabila sig. > 0,05 maka tidak terdapat perbedaan. Secara statistik perhitungan analisis diperoleh nilai sig. 0,000 artinya ada perbedaan hasil belajar antara Kelas A menggunakan Model Pembelajaran Conventional dan Kelas B menggunakan model pembelajaran Discovery Learning $(0,000<0,05)$.

Agar rumusan masalah yang sudah diajukan dapat terjawab, maka dilakukan uji hipotesis dengan menggunakan analisis uji Two Way ANOVA. Berikut ini hasil analisis Two Way ANOVA dengan menggunakan SPSS 24.

Tabel 3. Tests of Between-Subjects Effects Dependent Variable: Hasil Belajar

\begin{tabular}{|l|c|c|}
\hline \multicolumn{1}{|c|}{ Source } & F & Sig. \\
\hline Corrected Model & 4.899 & .000 \\
Intercept & 25637.837 & .000 \\
Model & 20.201 & .000 \\
Motivasi & 3.606 & .001 \\
Model * Motivasi & 2.291 & .038 \\
Error & & \\
Total & & \\
Corrected Total & & \\
\hline
\end{tabular}

a. R Squared $=.844$ (Adjusted R Squared $=.672$ )

Untuk hipotesis pertama, apakah ada pengaruh model pembelajaran Discovery dan conventional Learning terhadap hasil belajar. Berdasarkan hasil pengujian hipotesis pada tabel 3 Tests BetweenSubjects Effect, diperoleh nilai Sig. sebesar $0,000<0,05$, sehingga dapat disimpulkan bahwa ada pengaruh hasil belajar PPKn siswa berdasarkan model pembelajaran.
Selanjutnya, untuk hipotesis kedua, apakah ada pengaruh model pembelajaran Discovery dan Conventional Learning terhadap motivasi siwa. Berdasarkan hasil pengujian hipotesis pada tabel 3 Tests Between-Subjects Effect, diperoleh nilai Sig. sebesar $0,001<0,05$, sehingga dapat disimpulkan bahwa ada pengaruh model pembelajaran terhadap motivasi.

Terakhir, untuk hipotesis ketiga apakah ada interaksi antara model pembelajaran Discovery dan Conventional Learning terhadap motivasi siswa dan hasil belajar. Berdasarkan hasil pengujian hipotesis pada tabel 3 Tests BetweenSubjects Effect, diperoleh nilai Sig. sebesar $0,038<0,05$, sehingga dapat disimpulkan bahwa ada interaksi model pembelajaran dengan motivasi terhadap hasil belajar PPKn siswa.

\section{KESIMPULAN}

Berdasarkan hipotesis yang diajukan serta hasil analisis data yang diperoleh dalam penelitian tentang Pengaruh model pembelajaran Discovery Learning, Conventional dan motivasi siswa terhadap hasil belajar PPKn siswa kelas VII di UPTD SMPN 1 Labang maka diperoleh hasil sebagai berikut:

1. Berdasarkan hasil dari analisis Two Way Anova, ada pengaruh model pembelajaran Discovery dan conventional Learning terhadap hasil belajar

2. Berdasarkan hasil dari analisis Two Way Anova, ada pengaruh model pembelajaran Discovery dan Conventional Learning terhadap motivasi siswa

3. Berdasarkan hasil dari analisis Two Way Anova ada interaksi model pembelajaran Discovery dan Conventional Learning terhadap motivasi siswa dan hasil belajar PPKn.

Pada hasil Uji Independent T-Tes secara statistik perhitungan analisis 
diperoleh nilai sig. 0,000 artinya ada perbedaan hasil belajar antara Kelas A menggunakan Model Pembelajaran Conventional dan Kelas B menggunakan model pembelajaran Discovery Learning $(0,000<0,05)$.
Selain itu hasil rata-rata dari setiap model pembelajaran dimana model Discovery Learning memiliki rata-rata 86,00 sedangkan model Conventional memiliki rata-rata 79,83.

\section{DAFTAR PUSTAKA}

Arikunto, S. 2013. Prosedur Penelitian Suatu Pendekatan Praktik. Edisi Revisi. Jakarta: PT. Rineka Cipta

Aswita, Effi Lubis. 2012. Metode Penelitian Pendidikan. Medan: Unimed Press.

Depdikbud. 2014. PERMENDIKBUD No.58 Th. 2014 tentang Kurikulum 2013 Sekolah Menengah Perrtama/Madrasah Tsanawiyah. [Online]. Tersedia: http://staff.unila.ac.id/ngadimunhd/files/2012/03/Permen-58-ttg-Kurikulum-SMP.doc. Diakses dari laman web tanggal 23 januari 2020.

Dimyati dan Mudjiono. 2006. Belajar dan Pembelajaran. Jakarta: Rineka Cipta (Edisi ketiga).

Djamarah, Syaiful Bahri dan Aswan Zain. 2010. Strategi Belajar Mengajar. Jakarta: Rineka Cipta.

Fitri, Mariza dan Derlina. 2015. Pengaruh Model Pembelajaran Discovery Learning Terhadap Hasil Belajar Siswa Pada Materi Pada Materi Pokok Suhu dan Kalor. Jurnal Inpafi, 3 (2), 89-96. Diakses melalui https://jurnal.unimed.ac.id pada tanggal 15 januari 2020.

Gijoh, Rienly. 2013. Motivasi, Kompetensi dan Budaya Kerja Pengaruhnya Terhadap Kepuasan Kerja Karyawan Outsourcing Pada Hotel Sintesa Peninsula Manado. Junal EMBA, 1 (4), 1963-1973. Diakses melalui https://ejournal.unsrat.ac.id Pada Tanggal 15 Januari 2020.

Halim, Soesilowati dkk. 2019. Pengaruh Model Pembelajaran Discovery Learning dan Number Head Together Terhadap Aktivitas, Motivasi dan Hasil Belajar Siswa. Jurnal Pijar MIPA, 14 (1), 55-61. Diakses melalui https://jurnalfkip.unram.ac.id Pada tanggal 15 Januari 2020.

Hamzah B. Uno. 2011. Teori Motivasi dan Pengukurannya: Analisis di Bidang Pendidikan. Jakarta: Bumi Aksara

Helmiati. 2016. Model Pembelajaran.Yogyakarta: Aswaja Pressindo

Hosnan, M. 2014. Pendekatan Saintifik dan Kontekstual dalam Pembelajaran Abad 21. Bogor: Ghalia Indonesia

Jalil, Muhamad dkk. 2016. Pengembangan Pembelajaran Model Discovery Learning Berbantuan tips Powerpoint Interaktif pada Materi Interaksi Makhluk Hidup dengan Lingkungan. Jurnal Refleksi Edukatika, 6 (2), 130-137. Diakses melalui https://jurnal.umk.ac.id pada tanggal 15 januari 2020.

Kurniasih, Imas dan Berlin Sani. 2014. Implementasi Kurikulum 2013 Konsep dan Penerapan. Surabaya: Kata Pena

Lestari, Indah. 2013. Pengaruh Waktu Belajar dan Minat Belajar Terhadap Hasil Belajar Matematika. Jurnal Formatif, 3 (2), 115-125. Diakses melalui https://journal.lppmunindra.ac.id pada tanggal 15 Januari 2020.

Nasution, S. 1982. Berbagai Pendekatan Dalam Proses Belajar Mengajar. Edisi Pertama. Jakarta: Bina Aksara

Nurgiansah, T. H. (2021). Pelatihan Penelitian Tindakan Kelas Bagi Guru Pendidikan Kewarganegaraan Di Sekolah Menengah Atas Se-Kabupaten Bantul. BERNAS: Jurnal 
Pengabdian Kepada Masyarakat, 2(1), 28-33. https://doi.org/10.31949/jb.v2i1.566

Nurgiansah, T. H., Hendri, \& Khoerudin, C. M. (2021). Role Playing Dalam Pembelajaran

Pendidikan Pancasila dan Kewarganegaraan. Jurnal Kewarganegaraan, 18(1), 56-64. https://doi.org/10.24114/jk.v18i1.22597

Nurgiansah, T. H., Pratama, F. F., \& Iman, A. S. (2021). Penelitian Tindakan Kelas Dalam

Pendidikan Kewarganegaraan. Jurnal Pendidikan Pancasila Dan Kewarganegaraan, 2(1), 10-23.

Nurgiansah, T. H., \& Sukmawati. (2020). Tantangan Guru Pendidikan Kewarganegaraan Di Masa Adaptasi Kebiasaan Baru. Jurpis: Jurnal Pendidikan Ilmu Sosial, 17(2), 139-149.

Nuryadi, dkk. 2017. Dasar-dasar Statistik Penelitian. Yogyakarta: Sibuku Media

Priyono. 2016. Metode Penelitian Kuantitatif. Sidoarjo: Zifatama Publishing

Putrayasa, I Made. 2014. Pengauh Model Pembelajaran Discovery Learning dan Minat Belajar

Terhadap Hasil Belajar IPA Siswa. Mimbar PGSD Universitas Pendidikan Ganesha.

Riduwan dan Sunarto. 2012. Pengantar Statistik untuk Penelitian Pendidikan, Sosial, Komunikasi, Ekonomi dan Bisnis. Bandung: Alfabeta

Rosarina, Gina dkk. 2016. Penerapan Model Discovery Learning untuk Meningkatkan Hasil

Belajar Siswa Pada Materi Perubahan wujud Benda. Jurnal Pena Ilmiah, 1 (1), 371-380.

Diakses melalui https://ejournal.upi.edu Pada Tanggal 15 Januari 2020.

Salmon, A. et al. 2012. Belajar Dan Pembelajaran Matematika Model Pembelajaran Discovery

Learning. Makalah Universitas Patimura Ambon: tidak diterbitkan.

Samsudin, Salidi. 2010. Manajemen Sumber Daya Manusia. Bandung Penerbit Pustaka Setia

Samsuri. 2011. Pendidikan Karakter Warga Negara. Yogyakarta: Diandra Pustaka Indonesia

Sardiman. 2011. Interaksi dan Motivasi Belajar Mengajar. Jakarta : PT Rajagrafindo

Sardiman. 2012. Interaksi dan Motivasi Belajar Mengajar. Jakarta: Rajawali Pers

Siyoto, Pandu dan Ali Sodik. 2015. Dasar Metode Penelitian. Yogyakarta: Literasi Media Publishing

Subagio. 2011. Peran Pendidikan dalam Menciptakan Sumber Daya Manusia yang Berkualitas.

Diakses dari http://subagio-subagio.Blogspot.com. pada tanggal 16 April 2020, Jam 09:30 WIB.

Sudaryono. 2017. Metodologi Penelitian. Jakarta: PT Raja Grafindo Persada.

Sugiyono. 2013. Metode Penelitian Pendidikan. Bandung: Alfabeta

Sugiyono. 2016. Metode Penelitian Kuantitatif, Kualitatif dan R\&D. Bandung: Alfabeta

Suradi. 2019. Pendidikan Kewarganegaraan Sebagai Pendidikan Nilai dan Pendidikan Hukum dalam Mewujudkan Warga Negara yang Cerdas dan Baik (Smart and Good Citizen).

Jurnal Pemikiran dan Penelitian Ilmu-ilmu Sosial, Hukum, \& Pengajarannya. Volume XIV Nomor (2), Oktober 2019 (halaman 112 - 121) diakses melalui https://ojs.unm.ac.id pada tanggal 16 April 2020 jam 09.55 WIB.

Susanto, Hadi. 2016. Model Pembelajaran Discovery Learning. Diakses melalui https://bagawanabiyasa.wordpress.com pada tanggal 12 Februari 2020

Sri Widyastuti, Ellyza. 2015. Penerapan Model Pembelajaran Discovery Learning pada Materi

Konsep Ilmu Ekonomi. Prosiding Seminar Nasional 9 Mei 2015. Universitas Negeri Surabaya.

Undang-undang Dasar Negara Republik Indonesia Tahun 1945

Veermans, K. 2003. Intelligent Support For Discovery Learning. Twente: Twente University Press

Winataputra, Udin S. 2014. Pembelajaran PKN di SD. Jakarta: Universitas Terbuka 
Wagiran. 2013. Metodologi Penlitian Pendidikan: Teori dan Implementasi. Yogyakarta: CV Budi Utama

Wartono. 1999. Metode Pembelajaran. Jakarta : Depdikbud. 